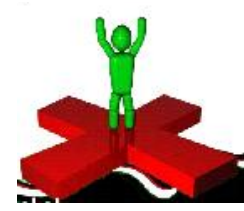

\title{
Effect of consumption of dehydrated green leaf mixture on the hemoglobin levels of the anemic adolescent girls
}

\section{PALLAVI JOSHI AND BEENA MATHUR}

See end of the paper for authors' affiliation Correspondence to : PALLAVI JOSHI P.G. Department of Home Science, University of Rajasthan, JAIPUR (RAJASTHAN) INDIA
ABSTRACT : The present study was designed to investigate the efficacy of leaf mixture (LM) on the hemoglobin $(\mathrm{Hb})$ levels of anemic adolescent girls. The LM was prepared by the combination of the leaf powders of four under utilized leaves of beetgreens (Beta vulgaris), carrot(Daucus carota), cauliflower (Brassica oleracea) and turnip (Brassica rapa) in the ratio of 1:2:1:1, respectively. The study was done in a Randomized Experimental Setting on the adolescent girls of poor communities residing in the urban slums of Jaipur city. The baseline investigations included measurement of height weight and $\mathrm{Hb}$ levels. The $\mathrm{Hb}$ levels of the anemic girls were measured every month for a period of four months of intervention and were compared with the $\mathrm{Hb}$ levels of the control group. The results revealed a significant improvement in the $\mathrm{Hb}$ levels of experimental group as compared to the control group $(\mathrm{P} \leq 0.01)$.

How to cite this paper : Joshi, Pallavi and Mathur, Beena (2015). Effect of consumption of dehydrated green leaf mixture on the hemoglobin levels of the anemic adolescent girls. Internat. J. Med. Sci., 8(1\&2) : 10-19.

KEY WORDS :

Under utilized, Beta

vulgaris, Daucus

carota, Brassica

oleraces, Brassica

rapa, Hemoglobin 